\title{
Avaliação revela impacto de um programa de formação de professores
}

\author{
Marli André*
}

\section{Resumo}

$\bigcirc$ presente texto pretende mostrar o potencial dos estudos de caso para revelar mudanças em contextos escolares e em concepções e práticas de professores que participaram do PROFORMAÇÃO - Programa de Formação de Professores em Exercício. A primeira parte do texto descreve brevemente o Programa de Formação que se destina a certificar professores leigos em exercício nas escolas das regiões Norte, Nordeste e Centro Oeste do país. Na segunda parte são apresentados os procedimentos metodológicos utilizados na realização de seis estudos de caso, que incluíram visitas às salas de aula dos cursistas, entrevistas, análises de memoriais e aplicação de testes de desempenho. A terceira parte do texto discute os principais resultados do estudo avaliativo: mudanças em concepções e práticas pedagógicas dos professores, melhoria em suas habilidades de escrita e em sua auto-estima, valorização da cultura local e das experiências dos alunos e efeitos positivos nas políticas locais e nos contextos escolares.

Palavras-chave: Estudos de caso. Formação de professores. Avaliação externa.

\section{External evaluation discloses the impact of a teacher education program Abstract}

Taking into consideration an external evaluation of a Teacher Education Program, this paper intends to show the usefulness of case studies to appraise changes in teachers' perspectives and practices and to disclose the social impact of the program. First, a brief description of the Teacher Education Program shows that it associates self instructional material and group meetings. Next, the paper presents the Program evaluation procedures: six case studies were conducted in three different states in the country, including classroom observations; analysis of teachers' written memories; interviews with teachers, tutors and local staff; and administration of teacher's written tests. The last part of the paper discusses the case studies main outcomes: changes in teachers' conceptions and practices; improvement in their writing abilities; improvement in teachers' self confidence; increasing teachers' evaluation of local culture and pupils' experiences; and positive effects in local policies and in schools contexts. Keywords: Case studies. Teacher education. Evaluation program.

\footnotetext{
* PhD, Center for Instructional Research and Curriculum Evaluation, University of Illinois; Prof. do Programa de PósGraduação em Educação, PUC-SP. E-mail: marliandre@pucsp.br
} 


\section{Evaluación externa señala el impacto de un programa de formación docente Resumen}

Este artículo intenta demostrar el potencial de los estudios de caso para revelar cambios en los contextos escolares y en las concepciones y prácticas de los maestros que frecuentaran el PROFORMAÇÃO - programa que asocia aprendizaje autodirigida y encuentros colectivos. En la primera parte hay una descripción del Programa que visa certificar los maestros que actúan en las regiones más pobres del país. La segunda parte presenta la metodología de la investigación: seis estudios de caso fueron conducidos en tres diversos estados del país, incluyendo observaciones de las aulas; análisis de memoriales escritos por los maestros; encuestas con todos los seguimientos que participaran de la implantación del programa y aplicación de testes de simulación didáctica a los maestros. La tercera parte discute los resultados principales de la evaluación: cambios en las concepciones y prácticas de los maestros; mejora en sus habilidades de escritura y en su autoestima; valoración de las culturas locales y de las experiencias de los estudiantes y efectos positivos en políticas locales y en los contextos de las escuelas. Palabras clave: Estudios de caso. Formación docente. Evaluación externa.

\section{Introdução}

Estudos de Caso podem ser usados em avaliação ou pesquisa educacional para descrever e analisar uma unidade social, considerando suas múltiplas dimensões e sua dinâmica natural. Na perspectiva das abordagens qualitativas e no contexto das situações escolares, os estudos de caso, que utilizam técnicas etnográficas de observação participante e de entrevistas intensivas, possibilitam reconstruir os processos e as relações que configuram a experiência escolar diária.

Se o interesse é investigar fenômenos educacionais no contexto natural em que ocorrem, os estudos de caso podem ser instrumentos valiosos, pois o contato direto e prolongado do pesquisador com os eventos e situações investigadas possibilita descrever ações e comportamentos, captar significados, analisar interações, compreender e interpretar linguagens, estudar representações, sem desvinculá-los do contexto e das circunstâncias especiais em que se manifestam. Assim, permitem compreender não só como surgem e se desenvolvem esses fenômenos, mas também como evolvem num dado período de tempo. São, portanto, instrumentos preciosos tanto para desvelar rotinas e inovações quanto para aferir mudanças em comportamentos e práticas ao longo do tempo.

$\bigcirc$ presente texto pretende mostrar o potencial dos estudos de caso para revelar mudanças em concepções e práticas de professores que participaram do PROFORMAÇÃO - Programa de Formação de Professores em Exercício, e para mostrar seu impacto em regiões desprovidas do país.

\section{O que é o PROFORMAÇÃO?}

Operando na modalidade de educação a distância, com dois anos de duração, - PROFORMAÇÃO é um curso de nível médio, destinado à formação de professores 
leigos que atuam nas quatro primeiras séries do ensino fundamental, pré-escolar e classes de alfabetização, das regiões Norte, Nordeste e Centro-Oeste do Brasil. Na primeira fase do Programa, de 2000 a 2002 foram atendidos cerca de 27.000 professores.

O PROFORMAÇÃO compõe-se de material auto-instrucional (32 Guias de Estudo, 32 vídeos e 32 Cadernos de Verificação da Aprendizagem) reunidos em 4 módulos, semestrais. Cada módulo engloba: a) uma fase intensiva de 10 dias com atividades presenciais para o professor cursista (PC), realizadas em janeiro e julho, nas Agências Formadoras (AGF), sob a coordenação de professores formadores (PF); b) uma fase continuada distribuída por todo o semestre, abrangendo atividades auto-instrucionais de estudo individual dos Guias de Estudo, elaboração de memorial, provas bimestrais e atividades coletivas quinzenais, com a supervisão de um tutor. Além de realizar reuniões quinzenais para tirar dúvidas sobre os Guias de Estudo, orientar a elaboração do memorial e propiciar discussões sobre a prática, cada tutor visita mensalmente a sala de aula do grupo de 10 ou 15 cursistas pelos quais é responsável.

\section{A proposta pedagógica do PROFORMAÇÃO}

O PROFORMAÇÃO parte de uma concepção de educação que

- busca a melhoria da prática pedagógica e o sucesso na aprendizagem dos alunos;

- valoriza as experiências culturais e os conhecimentos prévios do Professor Cursista;

- promove a reflexão teoria/prática à luz dos conhecimentos integrantes do currículo - contribui para o resgate da auto-estima do Professor Cursista;

- estimula a participação do Professor Cursista na vida da comunidade e em sua luta por melhores condições de vida e exercício da cidadania.

\section{Estrutura organizacional}

A estrutura organizacional do PROFORMAÇÃO supõe a participação de três instâncias:

- Componente Municipal - envolve o Órgão Municipal de Educação (OME) na Secretaria Municipal de Educação e o corpo de tutores. É responsável pela implementação do PROFORMAÇÃO no âmbito do município.

- Componente Estadual - composto pela Equipe Estadual de Gerenciamento do PROFORMAÇÃO (EEG), na Secretaria Estadual de Educação, Agências Formadoras e a Comissão Estadual do Proformação. Coordena e monitora os trabalhos no âmbito estadual.

- Componente Nacional - integrado pela Comissão Nacional do PROFORMAÇÃO (CNP), uma Instituição de Avaliação (IA) e o Fórum Nacional do PROFORMAÇÃO. Esse componente é encarregado da articulação política e institucional, responsável pela elaboração da proposta técnica e financeira do Programa, assim como pela definição da estratégia de sua implantação, e pelo monitoramento e avaliação de todas as suas ações.

Esses três componentes atuam de forma articulada na gestão do Programa.

\section{Avaliação externa do PROFORMAÇÃO: estudos de caso}

Desde o início de sua implementação, o PROFORMAÇÃO foi submetido a uma avaliação externa, conduzida por especialistas, com o objetivo de investigar o alcance 
das metas definidas e fazer as correções necessárias ainda durante o processo. Integraram a avaliação externa, estudos com perspectivas diferenciadas e complementares, a saber: pesquisa de opinião com todos os atores envolvidos, estudos de caso em escolas e comunidades, entrevistas e análises estatísticas dos dados de desempenho dos professores cursistas colhidos no Sistema de Informações do PROFORMAÇÃO (SIP).

presente texto concentrar-se-á num dos componentes da avaliação: os Estudos de Caso, que buscaram identificar possíveis relações entre o processo de qualificação profissional veiculado pelo PROFORMAÇÃO e a prática de sala de aula do cursista. A intenção era verificar, em última instância, se os objetivos do Proformação estavam sendo alcançados; em especial aqueles objetivos que dizem respeito à elevação do nível de conhecimento e da competência profissional dos docentes/cursistas e à meIhoria do processo ensino aprendizagem e do desempenho escolar dos seus alunos.

Os estudos de caso focalizaram as práticas dos professores cursistas no cotidiano de sua sala de aula, mas não deixaram de considerar aspectos do contexto socioinstitucional dos cursistas, efeitos das políticas locais e do sistema de tutoria, todos eles com grande influência na constituição da identidade profissional e no desempenho desses professores.

$\mathrm{Na}$ condução dos estudos de caso, o pesquisador mantém um contato direto e prolongado com os sujeitos e as situações, o que the permite traçar um raio-X do cotidiano escolar e ainda fazer comparações e aproximações ao longo do tempo.

\section{Escolha das unidades de análise}

A escolha dos locais que constituíram os estudos de caso foi pautada nos seguintes critérios:

- Dois estados que iniciaram o Programa em janeiro de 2000 (Grupo I): foram escolhidos o Acre, na região Norte e o Ceará, na região Nordeste.

- Um estado que iniciou o Programa em julho de 2000 (Grupo II): selecionou-se a Bahia por ser o estado com o maior número de cursistas.

Em cada um destes estados foram selecionadas duas Agências Formadoras (AGFs), o que resultou na realização de seis estudos de caso. A seleção das duas AGFs obedeceu aos seguintes critérios: uma por ser considerada boa na opinião de pessoas chaves envolvidas no processo, e outra escolhida aleatoriamente. A escolha das escolas e dos professores cursistas (PCs) atendeu ao critério geográfico- 1 AGF do norte e 1 do sul do estado- e às condições de acesso para as visitas às escolas.

\section{Metodologia de coleta de dados}

Os dados foram coletados em três momentos por seis pesquisadoras que, após passarem por um processo de seleção, participaram de uma sessão de treinamento de 8 horas com a coordenadora da pesquisa. Nessa sessão, receberam informações orais e escritas sobre os objetivos e a estrutura do PROFORMAÇÃO, e material ilustrativo de divulgação do Programa. Também fez parte do treinamento, a discussão da abordagem de estudo de caso, das tarefas e responsabilidades dos pesquisadores de campo, a definição do cronograma de trabalho e dos procedimentos de coleta de dados, que incluíram: 
- Registros escritos de observação da prática pedagógica do professor, considerando conteúdo abordado, usos do espaço, estratégias de gestão de classe, formas de interações sociais.

- Entrevistas com cursistas das classes observadas e com seus tutores, tentando verificar suas expectativas e opiniões sobre o Programa.

- Aplicação de teste de simulação didática aos cursistas para verificar seus conhecimentos do ensino de português, matemática e de didática tanto no início quanto ao final de um ano de participação no Programa.

- Coleta e análise de memoriais elaborados pelos cursistas.

- Testes de auto-estima e de desempenho dos alunos, em português e matemática, no início e no final de um ano letivo.

No início do ano letivo de 2001 foi feita uma visita às escolas de seis Agências Formadoras (AGFs) selecionadas para constituir os estudos de caso. Nova visita foi realizada às mesmas escolas, ao final do ano letivo de 2001, com o propósito de registrar os avanços ocorridos no período. Em junho de 2002 foi realizada uma terceira visita às escolas de uma das AGFs, para acompanhar mais de perto as mudanças e analisar, com os participantes, o impacto do PROFORMAÇÃO.

Cada visita envolveu a permanência da pesquisadora, por aproximadamente 10 dias, em período integral, na região em que ficava a escola dos cursistas, o que resultou num mínimo de 80 horas de observação em cada local investigado. A pesquisadora também acompanhou uma das reuniões presenciais, ao final de um semestre, momento em que realizou observação do encontro e entrevistas com professores formadores. Nas escolas em que houve uma terceira visita, o total de observação foi de cerca de 120 horas.

Cada uma dessas visitas era precedida por uma reunião de todas as pesquisadoras com a coordenadora da pesquisa para planejamento conjunto das atividades, organização do material para o trabalho de campo e revisão dos procedimentos de coleta de dados. Após a visita, as pesquisadoras se reuniam novamente com a coordenadora da pesquisa para discutir os resultados do trabalho de campo e para planejar a elaboração dos relatórios individuais. Coube à coordenadora a sistematização dos dados dos seis relatórios, numa publicação-síntese.

\section{Apresentação dos dados}

Os dados aqui apresentados reúnem as informações coletadas nas visitas do início e do final do ano letivo as seis AGFs selecionadas. Reúnem ainda dados de análise de memoriais dos cursistas, dos resultados dos testes de simulação didática e da terceira visita feita a uma das AGFs. Procuram apontar as mudanças observadas no contexto de trabalho dos professores cursistas, em sua prática pedagógica, em seu desempenho didático, em suas concepções pedagógicas, na escrita de memoriais, assim como no processo de constituição de sua identidade profissional.

\section{Mudanças na prática pedagógica}

Tanto as observações feitas nas visitas às escolas dos professores cursistas, quanto os resultados dos testes de simulação didática, assim como a análise dos memoriais atestam mudanças muito positivas na prática pedagógica dos cursistas: a) no planejamento e preparação das atividades docentes; b) na gestão de sala de aula (que 
inclui a organização do espaço, o uso de material concreto e de outros recursos, a interação professor- aluno e aluno- aluno e o trabalho didático com as diferenças); e c) na articulação do conteúdo com as experiências culturais dos alunos.

\section{Planejamento e preparação das atividades}

Os dados coletados permitem concluir que o planejamento foi totalmente incorporado à vida dos cursistas. Nas visitas às salas de aula percebeu-se claramente que as atividades eram preparadas com antecedência e que os professores seguiam uma diretriz em suas aulas. É o que atestam alguns relatos de campo:

Uma das atividades observadas na classe da professora E foi a "Linha do tempo", trabalhada ao mesmo tempo com as quatro séries. Conforme seu plano de aula, o objetivo era fazer com que as crianças conhecessem o verdadeiro significado de sua existência, conhecendo a sua história. Ela conta primeiro a história da vida dela, desenhando na lousa as etapas mais importantes: nascimento, com 1 ano aprendi a andar, com 2 anos a falar, com 7 a entrada na escola, etc. Para trabalhar esse conteúdo com todos os alunos, ela diversificou as atividades. Para os alunos da $2^{a}, 3^{a}$ e $4^{a}$ distribuiu tiras já cortadas de papel pardo, que as crianças dobraram em partes conforme o número de anos que tinham e em cada parte desenharam e escreveram as etapas de sua vida. Para as de $1^{a}$ série distribui uma folha de papel almaço e indica a cada um onde escrever o nome e a idade. (Diário de Campo de Rio Branco, AC).

Ao escrever seu memorial, uma cursista reconhece que mudou sua concepção de planejamento:

Antes, eu fazia um plano diário às avessas: primeiro eu trabalhava e depois eu registrava [...] Só com o PROFORMAÇÃO é que aprendi a fazer e a utilizar um plano. Fiquei mais independente, mais autônoma, mais segura. (AGF de Gandu, BA).

Uma tutora destaca a mudança de atitude dos professores cursistas quanto ao planejamento:

Nesses últimos meses muita coisa mudou, sim, principalmente na prática dos professores, no planejamento deles. Antes faziam pressionados, porque tinham que fazer. Hoje fazem espontaneamente, sentem-se mais seguros quando planejam a aula [...]

Antes do PROFORMAÇÃO era só livro didático, hoje são mais flexíveis em relação à prática pedagógica. Antes a secretaria dava um plano pronto para eles fazerem. Hoje eles já se juntam na escola, por ex. os professores de $1^{a}$ série se reúnem e fazem seu plano mensal. (Tutora de Feira de Santana, BA).

Ao ser indagada sobre as eventuais mudanças nos professores cursistas, a diretora de uma das escolas confirmou que a principal mudança observada foi no planejamento das aulas:

Mudou muita coisa, principalmente o plano de aula. Outro dia uma professora me perguntou se depois que acabasse o PROFORMAÇÃO voltariam a fazer o roteiro e eu disse que não, que continuariam a fazer planos de aula a preparar bem as atividades. 


\title{
Uso do espaço e gestão da sala de aula
}

A observação das salas de aula dos professores cursistas mostrou que, de maneira geral, a sua prática docente cotidiana foi positivamente afetada pelo PROFORMAÇÃO. Notou-se, por um lado uma tendência a reproduzirem em suas salas, as dinâmicas vividas nas reuniões da fase presencial e, por outro lado, aproveitarem as sugestões dos Guias de Estudo e dos vídeos do Programa. Observou-se em todas as salas um uso freqüente de trabalho em grupo, leitura e comentários de mensagens, disposição das carteiras em círculos ou semicírculos, decoração das salas com cartazes e trabalhos dos alunos, uso de materiais concretos.

As condições propícias à aprendizagem, seja pelo cuidado observado no ambiente da escola, seja pela estruturação do espaço de sala de aula estão presentes em vários relatos de campo, como o que se segue:

A escola estava limpa, com pintura nova e o pessoal de serviços gerais estava em ação [...] Nas salas de aula os professores trabalhavam em círculo: os alunos da $3^{a}$ série trabalhavam em grupo com uso do dicionário, os da $1^{\text {a }}$ série também trabalhavam em grupo e em seguida apresentavam seus trabalhos, o que demonstra alteração nas práticas de sala de aula. (Diário de campo de Sobral II, CE).

Outro diário de campo também enfatiza a organização do espaço de sala de aula para criar um ambiente estimulador à aprendizagem:

\begin{abstract}
Também estas professoras tentam criar um ambiente de letramento na classe. Há vários cartazes e murais espalhados pelas paredes: alfabeto maiúsculo e minúsculo, nomes de alunos conforme a inicial, nossa agricultura (desenho de árvores da região), correio Anjo da Guarda (cada aluno tem um envelope com seu nome onde os outros deixam mensagens), estações do ano (não adaptadas à região), produtos culturais e produtos naturais. Há também um varal com exposição de trabalhos dos alunos: ficha de identificação, minha história, a paisagem que vi no passeio. Por fim, um cartaz no alto de uma parede: SEJAM BEM-VINDOS. As professoras trabalham com os alunos dispostos ora em grupo, ora em semicírculo.(Diário de Campo de Gandu, BA).
\end{abstract}

Os memoriais registram exemplos de mudança no espaço de sala de aula que os cursistas atribuem ao PROFORMAÇÃO:

Através do estudo dos guias do curso, mudei completamente minha maneira de organizar o espaço da sala de aula, visto que passei a organizar as carteiras em círculo e não mais enfileiradas, os cartazes passaram a ser elaborados não só por mim, mas juntamente com os alunos, como o contrato didático e outros. Aprofundei ainda meus conhecimentos com o estudo da área de organização do trabalho pedagógico e passei a organizar cantinhos como: Cantinho da Exploração da Leitura e Recanto das Soluções Matemáticas. Tudo isso com o apoio e opiniões dos alunos. (Cursista de Cruzeiro do Sul, AC, Módulo IV, Unidade 1). 
Numa das escolas foi visível a mudança nas condições físicas e no ambiente de sala de aula, comparando-se a segunda visita com a primeira:

\begin{abstract}
Vários cartazes decoram as paredes, cartazes realizados pelas crianças, com temas sobre animais domésticos, selvagens, sobre a cidade e um grande mural sobre a família com figuras retiradas de revistas, mas que ilustram, como se fossem fotos, a família de cada criança da sala. Soube depois que este mural foi realizado em conjunto com pais e mães numa atividade coletiva sobre a família, realizada na escola. A sala da cursista tem agora um cantinho da leitura e dois varais com jornais e livros de historinhas. Há também um grande painel com uma arvore e o nome de todos os alunos. Noutro cantinho há fantoches e um quadro com a Declaração dos Direitos da Criança. (Diário de Campo de Quixadá, CE).
\end{abstract}

Considerando o aspecto formativo da avaliação externa, um dos principais objetivos da terceira visita feita a uma das AGFs foi a "devolutiva" dos dados, ou seja, a apresentação aos participantes, dos principais resultados dos estudos de caso. Um dos pontos destacados nesse momento foi que a avaliação revelou como aspecto positivo a re-estruturação do espaço de sala de aula pelos professores cursistas. Houve várias manifestações de apoio dos professores cursistas a essa conclusão.

\title{
Uso de materiais concretos
}

As observações de sala de aula revelaram ainda que os professores trabalhavam com material concreto, aproveitando os recursos disponíveis na comunidade para desenvolver os conteúdos e para valorizar a cultura local.

O depoimento de uma professora cursista, extraído do diário de campo de uma pesquisadora ilustra muito bem como ela utiliza material concreto para desenvolver os conteúdos, se servindo das experiências dos alunos e dos recursos locais:

\begin{abstract}
Antes, eu passava tarefa para eles na lousa, sentava e ficava esperando eles resolverem. Agora sou diferente, amiga, não sou tão prepotente. Eu mudei muito na dinâmica da aula. O que eu aprendo aqui eu adapto, eu faço a transformação. Em Ciências, por exemplo, quando eu ia trabalhar seres vivos, eu só levava as figuras do livro para eles olharem. Hoje eu levo plantas, até pintinho levei e também fomos ao zoológico no Parque Chico Mendes para ver de perto os animais. Também na matemática, nas atividades de divisão e subtração. Antes eu fazia no quadro, agora trabalho com tampinhas, tenho dinheiro falso, impresso, para trabalhar com compra e venda de objetos. A criança via o concreto, ia com embasamento feito no concreto. Trabalhava a venda de refrigerantes com eles. Dava notas de 5,00 para comprarem dos colegas refrigerantes de 1,00. Para a divisão trabalhei muito com pedrinhas, elas funcionam bem. (Diário de Campo de Rio Branco, AC).
\end{abstract}

\section{Trabalho diferenciado}

Nas classes multisseriadas, que eram maioria, observou-se que os professores cursistas lidavam muito bem com a diversidade intra e inter séries. Quer queira, quer não, nessas classes 
as diferenças estão mais visíveis e mais marcadas do que nas classes regulares e os professores se vêem frente ao desafio de atender alunos em estágios variados de aprendizagem. Nas salas observadas, eles pareciam enfrentar o desafio com muita naturalidade: atribuíam tarefas diferenciadas aos grupos, solicitavam aos alunos das séries mais adiantadas que auxiliassem seus colegas, corrigiam erros, reforçavam os acertos e mostravam bom manejo da situação.

Um extrato do diário de campo mostra que a professora organiza o espaço para atender alunos em diferentes estágios de desenvolvimento, estimula a participação e a cooperação entre os alunos e cria um ambiente favorecedor à aprendizagem:

Clara trabalha com alunos da $1^{a}$ série a $4^{a}$ série, uma classe multisseriada. Divide a sala ao meio e de um lado coloca os alunos de $1^{a}$ e $2^{a}$ e no outro os alunos de $3^{a}$ e $4^{a}$. O meio da sala fica livre para que ela circule. Há muita coisa escrita nas paredes da sala: cartazes, trabalhos de alunos, o alfabeto e outros textos. Na realização das atividades estimula a participação dos alunos: solicita que falem, que emitam suas opiniões. Realiza alguns trabalhos em grupo e inclusive estimula a cooperação entre as séries. Em uma das atividades pediu que os alunos da $2^{a}$ série ajudassem os alunos da $1^{a}$ série. Para ela os que sabem mais auxiliam aos que sabem menos. (Diário de Campo de Feira de Santana, BA).

memorial de uma cursista que trabalha com classe multisseriada registra 0 sucesso de uma atividade realizada em duplas, em que os alunos deveriam criar problemas, conforme sugestão dos Guias de Estudo:

Foi aquele barulhão, todos participaram, acharam interessante, sentiram-se motivados e até pediram bis. Eu, é claro, fiquei muito feliz com os resultados, pois eles tiveram facilidade e muita rapidez, tanto para criar como para responder aos problemas e com esse resultado pude perceber e aprender que o sucesso do aluno depende muito do professor e que quando está acontecendo alguma coisa errada na aprendizagem de uma criança a culpa pode ser nossa. Basta refletirmos, pedir ajuda aos colegas, procurar conhecer melhor a criança e experimentála por todos os lados. (AGF de Gandu, BA, Módulo III, Unidade 6).

\section{Relação professor aluno}

Além de criar um espaço acolhedor, com vários estímulos à aprendizagem, e realizar atividades diferenciadas para atender alunos em diferentes níveis de aprendizagem, os professores cursistas incentivavam a participação dos alunos e o trabalho em grupo, mantinham um clima de confiança e respeito mútuo e desenvolviam relações harmoniosas com os alunos. Um extrato do diário de campo ilustra o "clima" de sala de aula:

Percebemos que a relação estabelecida entre o professor e seus alunos se caracteriza pela dimensão do respeito mútuo. Os papéis são claros: o professor conduz sua prática pedagógica mobilizando o grupo para um ritmo de aprendizagem necessário ao nível de $4^{a}$ série, e este grupo responde satisfatoriamente, envolvendo-se com o conteúdo, as atividades que são especificamente trabalhadas na lousa com a mediação do professor. No desenvolvimento das atividades o professor incentiva os alunos na resolução dos exercícios, atende-os individualmente e em seguida, só após todos conseguirem respon- 
der, ele vai para a lousa fazer a correção coletiva. Na correção, o grupo participa fervorosamente. São 16h15., os alunos pedem para sair mais cedo, já que vai haver celebração de uma missa na comunidade. O professor responde que ainda é cedo e começa a trabalhar o cálculo da área através da resolução de problemas, já que até então vinha trabalhando através da fórmula. Só após a correção coletiva é que liberou a turma (Diário de Campo de Sobral II, CE).

memorial de uma cursista mostra a influência do material do Proformação na mudança de concepção sobre o ensino e nas relações de sala de aula:

[...] o professoré apenas um mediadore não o dono da verdade. Deixei de ver as crianças como alunos-jarros como diz a área temática de Linguagens e Códigos, onde o professor despeja conhecimentos. Passei a ter mais respeito por eles, de acordo com suas individualidades, dando-lhes oportunidades de questionamento, mudando até mesmo a maneira de avaliar o aluno. (Cruzeiro do Sul, AC, Módulo Il, Unidade 7).

\section{Articulação dos conteúdos com as experiências culturais dos alunos}

Tanto nas visitas feitas às escolas quanto no exame dos memoriais foram encontradas situações em que o cursista procurava articular os conteúdos escolares com a realidade dos alunos, aproveitando os recursos da comunidade e valorizando a cultura local.

Apresentamos como ilustração, um extrato do diário de campo da pesquisadora, que acompanhou uma Feira de Artes:

A exposição está singelamente bonita. O que chama a atenção é que não se vê a homogeneização de trabalhos tão comum nesse tipo de evento. São trabalhos confeccionados pelos alunos com materiais da própria região (argila, samambaia do mato, madeira), utilizando técnicas que passam de "pai para filho", ou com sucata (garrafas plásticas, por exemplo), sob orientação das professoras. Destaca-se a liberdade de criação que os alunos tiveram. (Diário de Campo de Gandu, BA).

Há ainda vários exemplos dessas situações nos memoriais elaborados pelos cursistas, como as destacadas abaixo:

Dei uma aula de ciências a meus alunos com rótulos de produtos alimentícios. Pedi para eles trazerem de casa embalagens dos produtos consumidos pela família [...], pedi que formassem grupos de três e que copiassem no caderno tudo o que estivesse escrito nas embalagens, destacando ingredientes, marcas e pesos. Logo surgiram perguntas do tipo: 'o que é aromatizante?' Dei uma aula explicativa, mostrando a importância de comermos alimentos fabricados em nossas casas. Juntos construímos uma receita de como conservar carne e, a partir daí, surgiram várias receitas que eles próprios escreveram, dizendo o que suas mães costumavam fazer para conservar alimentos: peixe, frutas, leite etc. Com a receita pronta, cada grupo comparou sua receita com a receita contida 
nas embalagens e juntos chegamos à conclusão de que os produtos caseiros são mais saudáveis e fazem muito bem ao nosso organismo. (PC, AGF de Gandu, Módulo I, Unidade 3).

Outro exemplo encontrado no registro de uma cursista mostra a influência do curso oferecido pelo PROFORMAÇÃO nas atividades de sala de aula:

Com a oportunidade de escrever meu projeto sobre a lagoa de tratamento de esgoto do nosso bairro, é claro que trabalhei o meio ambiente com meus alunos e com a comunidade. Quando todas as pessoas aprenderem a preservar o meio ambiente em que vivem, sem dúvida tudo vai ser diferente, o mundo será menos poluído. (PC, Quixadá, CE, Módulo IV, Unidade VII).

Também há registros de atividades que consideram as experiências culturais dos alunos no seguinte extrato:

Ao trabalhar com mapas levei os alunos a identificar a localização e a posição da escola, do bairro e da rua onde está localizada a sua própria casa. Foi um trabalho gratificante, pois os alunos chegaram a descobrir lugares, nomes de ruas até então desconhecidos ou ignorados do seu conhecimento. (Cruzeiro do Sul, AC, Módulo IV, Unidade 1).

\section{Mudanças nas concepções dos professores}

Além das mudanças na prática pedagógica dos professores cursistas, os dados de observação, entrevista e a análise de memoriais permitiram identificar várias mudanças nas concepções pedagógicas dos professores cursistas.

\section{Mudança na concepção do papel do professor}

Nos memoriais dos professores cursistas encontramos registros de mudanças evidentes: de uma visão de que o professor é um missionário para uma visão de que o professor é um profissional:

Quando iniciei a carreira de professora era inexperiente, mas procurava fazer o melhor. E tinha uma visão de que professor(a) trabaIhava por amor. Afinal o salário era tão pequeno. Se bem que nunca foi grande, mas hoje, em relação ao passado, é bem melhor. Mas este pensamento já tomou outra direção. Hoje vejo que professor tem que trabalhar porque é um profissional. E que ele tem que se capacitar para melhor ensinar, para ter um salário maior, para ser visto e reconhecido pelo seu talento e capacidade. Professor tem que ser livre para falar de liberdade a seus educandos. E o Proformação tem alargado esta visão, fazendo com que me sinta importante e capaz. É só querer. (Quixadá, CE, Módulo II, Unidade 7).

memorial de outra cursista destaca o importante papel do professor na formação de cidadãos e na construção de uma sociedade democrática:

Portanto, quando em nossa sociedade todos assumirem o seu papel de cidadão, com certeza teremos uma sociedade mais justa e mais democrática. Mas para que isso aconteça depende também do professor, pois ele é uma das peças mais importantes perante a 
sociedade [...] se continuarmos tendo informações tão gratificantes como estamos recebendo, com certeza saberemos realizar o nosso papel de educadores e teremos uma sociedade mais justa. (Rio Branco, AC, Módulo I, Unidade 8).

\section{Mudanças na concepção de ensino e aprendizagem}

Ao registrar suas principais mudanças, uma cursista deixa evidente sua nova concepção de ensino aprendizagem:

Uma coisa que mudou na minha maneira de ensinar foi incluir a vida dos alunos no currículo escolar, porque aprendi que o aluno é a peça principal da escola e precisamos dar espaços para que ele cresça e construa sua história, dando sua contribuição para a formação de uma sociedade democrática e justa. (Gandu, BA, Módulo I, Unidade 3).

Esse depoimento mostra que a concepção de ensino aprendizagem veiculada pelos Guias de Estudo foi incorporada pela cursista.

\section{Mudança na concepção de avaliação}

Os memoriais trazem vários exemplos de como a passagem pelo Proformação afetou a concepção de avaliação dos professores cursistas. Eles destacam as novas formas de avaliar; a ampliação do âmbito da avaliação, para além dos muros da escola; o caráter formativo da avaliação que leva a um aprimoramento das atitudes de professores e alunos. Num dos memoriais há o seguinte registro:

Finalmente vou falar de um assunto muito comentado que é a avaliação escolar. Graças a Deus o PROFORMAÇÃO vem-nos orientando melhor sobre a avaliação, para a nossa atuação profissional. Sabemos da importância que tem a avaliação para a escola, mas também sabemos que a maneira de trabalhar com avaliação mudou muito. Não existe mais aquela avaliação só de provas escritas. Hoje a avaliação está presente em todo nosso cotidiano escolar. Hoje existem vários tipos de você professor poder avaliar um aluno; um dos exemplos: quando todos participam, todos avaliam e são avaliados, conseqüentemente, estes alunos se tornam responsáveis e comprometidos com as propostas que surgem. A avaliação antecede, acompanha e sucede todo o trabalho pedagógico possuindo funções diferentes de como trabalhar e avaliar. (Quixadá, CE, Módulo III, Unidade 7).

Em memoriais de outra AGF também há registros significativos sobre as mudanças na concepção de avaliação, como o que segue abaixo:

Antes, quando eu pensava em avaliação, as idéias que surgiam na minha cabeça eram provas, notas, aprovação e reprovação. Hoje aprendi, através do Proformação, que avaliar é refletir sobre uma determinada realidade. É a avaliação que vai nos permitir fazer sugestões, encaminhamentos e decisões. A avaliação é um processo muito importante para a escola, professor e aluno, pois não só o aluno deve ser avaliado; é necessário que pensemos na avaliação, envolvendo tudo e todos que participam do processo educacional que acontece na escola, e assim ajudará o aluno a superar suas dificuldades. (Módulo III, Unidade 7). 


\section{Mudanças na auto-estima e valorização profissional}

$O$ crescimento e a valorização profissional e o aumento da auto-estima foram objetivos que o PROFORMAÇÃO alcançou de maneira contundente. Tanto nas entrevistas com professores cursistas e tutores, quanto nos relatos dos professores em seus memoriais, observa-se que o Programa significou para esses professores uma oportunidade de crescimento pessoal e profissional, uma possibilidade de realizar-se como profissionais e cidadãos.

Nos registros escritos pelos professores cursistas da Bahia pode-se identificar várias mudanças, reconhecidas por eles:

Hoje eu sou mais confiante no trabalho. O relacionamento com as pessoas com as quais convivi durante este tempo do curso foi ótimo, Mudei a minha prática pedagógica com as orientações da minha tutora que é uma pessoa maravilhosa, os professores formadores que nos orientaram muito.

Sim, hoje sou mais reflexiva em tudo que faço, sou compreensiva com meus alunos e com as pessoas com quem convivo.

Aprendi como tratar meus alunos respeitando as suas culturas, suas religiões, seus costumes porque são as pessoas com quem mais convivo. Estou desinibida ao falar em público, transformei a minha prática pedagógica, aprendi a conversar com as pessoas e estou muito feliz com a minha profissão, por ser agora uma professora capacitada.

Nos memoriais do Acre também há vários registros das mudanças que os professores cursistas apontam em sua vida pessoal ou na sua atividade profissional:

Em minha vida não está sendo diferente, as mudanças são contínuas. Adquiri o hábito de ler, estou tendo um diálogo mais aberto com as crianças e sou mais compreensiva. Assim não se pode negar a influência e a importância do PROFORMAÇÃO, que está sendo para mim a abertura de novos horizontes, enriquecendo minha bagagem cultural, dando-me subsídios teóricos para o desenvolvimento de minha prática pedagógica. (AGF Rio Branco, Módulo II, Unidade 7).

\section{Mudanças na auto-estima}

As novas aprendizagens e o aperfeiçoamento da prática pedagógica têm um efeito positivo na elevação da auto-estima dos docentes, como revelado na declaração da cursista:

A nossa auto-estima com o Proformação subiu um pouco. Antes a gente era vista como PS - professor suplementar, quer dizer, um tapa-buraco para todo professor que faltava. Na minha escola estou sendo mais respeitada e eu sinto que tenho mais domínio sobre o meu trabalho, sobre a minha sala. (Rio Branco, AC).

As mudanças vão se fazendo visíveis às próprias cursistas, que assinalam modificações em suas posturas nas atividades coletivas, nos trabalhos em grupo e nas reuniões da escola:

Era muito, muito tímida. Agora, com o PROFORMAÇÃO, e com o ajuntamento de gente, estou mais solta. Antes tinha vergonha de falar 
e que zombassem de mim [...] Agora sinto que estou mais segura para participar das reuniões na escola. (AGF de Quixadá, CE).

Observou-se que os professores cursistas em suas unidades têm sido solicitados pelos seus pares que cursam a educação superior, a auxiliá-los no desenvolvimento dos memoriais, a discutir na própria escola a temática do projeto pedagógico dentre outros. Esse fato pode ser comprovado pelo depoimento de uma tutora:

Os PC (professores cursistas) comentam em seus memoriais que foram muito discriminados por serem professores leigos. Hoje, quem está dando orientação sobre o Projeto político pedagógico são os PCs. Eles sofreram discriminação por serem leigos e hoje os colegas da escola já o respeitam. No passado tinham uma presença passiva nas reuniões da unidade escolar, se precisavam falar, falavam qualquer coisa. Hoje não, eles já elaboram um pouco melhor, a participação nas reuniões já é mais efetiva, sugerindo, oferecendo suas contribuições. (Tutora de uma AGF do Ceará).

Pode-se dizer que o PROFORMAÇÃO tem favorecido a conquista da cidadania por parte desses educadores agora reconhecidos publicamente como qualificados para 0 exercício da profissão. Além dos direitos legitimados, esta qualificação lhes confere o sentimento de pertencer a um grupo profissional e se sentirem, de verdade, parte dele:

Ah, minha vida se transformou depois do Proformação. Eu aprendi muito mais, eu aprendi a ser mais comunicativa, ser mais paciente, ser mais amorosa com as crianças. Realmente minha vida se transformou. Agora eu sou professora de verdade, já posso dizer que sou professora de verdade depois do Proformação. (AGF de Rio Branco, AC).

\section{Auto-estima e crescimento profissional}

crescimento profissional dos professores cursistas, que se reflete na elevação de sua auto-estima, fica muito evidente numa análise longitudinal dos memoriais.

Nos primeiros memoriais vários cursistas registram sentimentos de fé e de esperança e parecem acreditar que forças externas os auxiliarão a concluir o Programa. Alguns extratos de memoriais atestam isso:

Tenho fé em Jesus Cristo que no decorrer desses dois anos vou conseguir um bom desempenho [...] Espero que o Proformação neste módulo II continue contribuindo para que essas mudanças sejam constantes e que eu possa melhorar a cada dia não só como profissional, mas também como pessoa. (AGF de Cruzeiro do Sul, AC, Módulo I, Unidade 1 e Módulo II, Unidade 1).

Eu estou me desenvolvendo mais na prática pedagógica graças a nosso bom Deus. Espero melhorar mais em atividades com meus alunos. (Feira de Santana, BA, Módulo I, Unidade 1).

O curso para mim está sendo uma grande realidade na minha vida hoje, graças a Deus eu já me conscientizei desta mudança em minha vida e estou estudando muito para conseguir o meu objetivo que é terminar o curso. (Quixadá, CE, Módulo I, Unidade 8). 
Após o primeiro ano de curso, os cursistas deixam de apelar para forças externas e passam a manifestar sentimentos de confiança em si mesmos. Nos últimos memoriais diminuem as referências a Deus ou a outras forças externas; os cursistas parecem mais seguros de suas próprias aprendizagens e detentores de recursos próprios para efetuar as mudanças necessárias. Seguem alguns extratos dos memoriais:

O meu maior ganho neste curso é a aprendizagem. É um acompanhamento bem fortalecido onde estou tendo a oportunidade de adquirir novos conhecimentos para a minha vida profissional e de poder mostrar um trabalho de boa qualidade. (Quixadá, CE, Módulo III, Unidade 8).

[...] Como profissional seria hipócrita se dissesse que não cresci, pois passei a entender melhor o meu aluno, respeitando a individualidade de cada um, adquiri o hábito de ler mais, e obtive bons rendimentos na minha prática pedagógica com aulas mais dinâmicas. Aprendi a expor minhas idéias, enfim, foram vários conhecimentos obtidos. Tudo isso me leva a ter certeza de que o curso tem tido grande influência nessas mudanças e conhecimentos obtidos, creio que ao final do mesmo sairei não só com um diploma, mas sim, como uma profissional qualificada convicta do que irei fazer. (Cruzeiro do Sul, AC, Módulo III, Unidade 2). Graças aos estudos do PROFORMAÇÃO, adquiri novos conhecimentos muito importantes para a minha vida profissional, melhorando a minha prática pedagógica. E partindo desse pressuposto posso também melhorar o jeito de avaliar as atitudes das pessoas diante da sociedade. (Gandu, BA, Módulo III, Unidade 7).

\section{Mudanças na identidade profissional}

De um modo geral, percebe-se que o PROFORMAÇÃO criou situações que favorecem o processo de construção da identidade profissional dos professores cursistas. Considerem-se, por um lado, as oportunidades de interação propiciadas pelo Proformação, sobretudo nas reuniões quinzenais, em que os cursistas são estimulados a refletir sobre suas práticas, trocar experiências, compartilhar suas aprendizagens. Neste momento ele está constituindo- se como pessoa e como profissional. Considerem-se, por outro lado, os ricos momentos de elaboração do memorial, em que o professor cursista é instado a escrever a sua história, a analisar o seu percurso, a tomar consciência do seu processo de crescimento. Nesse movimento de voltar-se sobre si mesmo e sobre seu trabalho, ele vai construindo a sua identidade profissional.

As reuniões quinzenais parecem caracterizar-se como oportunidades ricas de troca de experiências de vida e de profissão entre os cursistas: "A troca de experiências e o apoio dos tutores ajuda muito. Consigo ver onde eu estava errando," diz uma das cursistas da Bahia. "Quando não dou conta, me apego com os colegas, com a experiência dos demais, com as tutoras," diz a outra.

Uma cursista do Ceará explicitou à pesquisadora que os processos interativos do Programa levaram ao crescimento do grupo de professores cursistas do qual participa. Salientou que é pela interação que se chega à aprendizagem, e que esta possibilita o desenvolvimento da autonomia: "Foi uma dificuldade doida. Fazia 13 anos que não estudava. Hoje, não, nos reunimos e respondemos aos CVAs. Não precisamos mais da tutora."

O que mais chama a atenção nesse depoimento é a manifestação de um processo de autonomia em desenvolvimento ("Não precisamos mais da tutora"). 


\section{Mudanças no desempenho dos professores cursistas}

Além de mudanças nas práticas e nas concepções pedagógicas dos professores cursistas, os estudos de caso possibilitaram verificar mudanças no seu desempenho, seja na resolução de questões relativas ao trabalho escolar cotidiano, seja na escrita dos memoriais.

Para aferir possíveis ganhos do cursista ao longo do Programa foi utilizado o Teste de Simulação Didática, instrumento organizado em forma de questões que simulam situações didático-pedagógicas do cotidiano escolar, referentes ao ensino de português, ensino de matemática e questões gerais de didática. $\bigcirc$ teste foi aplicado aos cursistas de 5 AGFs no início e no final do ano letivo de 2001 . Foram usadas duas formas paralelas de teste para possibilitar a comparação dos resultados: uma em março de 2001 ( $1^{\circ}$. momento) e a outra em novembro de 2001 ( $2^{\circ}$. momento). Em ambas há um total de 25 questões, das quais 10 relativas ao ensino de português, 10 relativas ao ensino de matemática, e 5 situações problema do cotidiano escolar.

Q Quadro 1 mostra o número de professores que responderam ao teste.

\begin{tabular}{|l|l|l|l|}
\hline Estado & AGF & \multicolumn{2}{|c|}{ Total de professores } \\
\hline & & Momento 1 & Momento 2 \\
\hline Bahia & Gandu & 21 & 20 \\
\hline & Feira de Santana & 20 & 20 \\
\hline Acre & Rio Branco & 27 & 24 \\
\hline Ceará & Quixadá & 38 & 31 \\
\hline & Sobral II & 29 & 25 \\
\hline Total & & 135 & 120 \\
\hline
\end{tabular}

Quadro 1 - Distribuição dos professores cursistas por estado e AGF. Fonte: Placco, André e Gatti (2002).

Os resultados dos testes de simulação didática mostram mudanças evidentes no desempenho dos cursistas.

\begin{tabular}{|l|c|c|c|c|c|c|c|}
\hline \multirow{2}{*}{ AGF } & \multicolumn{6}{|c|}{ Total de Respostas Adequadas } \\
\cline { 2 - 9 } & \multicolumn{6}{|c|}{$\begin{array}{c}\text { Momento 13.375 } \\
\text { respostas }\end{array}$} & \multicolumn{2}{c|}{$\begin{array}{c}\text { Momento 23.000 } \\
\text { respostas }\end{array}$} & Diferença \\
\hline & $\begin{array}{c}\text { Respostas } \\
\text { adequadas }\end{array}$ & $\begin{array}{c}N^{\circ} \\
\text { Profs. }\end{array}$ & $\begin{array}{c}\text { Média/ } \\
\text { professor }\end{array}$ & $\begin{array}{c}\text { Respostas } \\
\text { adequadas }\end{array}$ & $\begin{array}{c}N^{\circ} \\
\text { Profs. }\end{array}$ & $\begin{array}{c}\text { Média/ } \\
\text { professor }\end{array}$ & $\begin{array}{c}\text { da média/ } \\
\text { prof. }\end{array}$ \\
\hline Gandu & 213 & 21 & 16,3 & 346 & 20 & 17,3 & 1,0 \\
\hline Feira de Santana & 277 & 20 & 13,9 & 368 & 20 & 18,4 & 4,5 \\
\hline Rio Branco & 337 & 27 & 12,5 & 386 & 24 & 16,1 & 3,6 \\
\hline Quixadá & 439 & 38 & 11,6 & 545 & 31 & 17,6 & 6,0 \\
\hline Sobral II & 342 & 29 & 11,8 & 420 & 25 & 16,8 & 5,0 \\
\hline Total & 1608 & 135 & 11,9 & 2065 & 120 & 17,2 & 5,3 \\
\hline
\end{tabular}

Quadro 2 - Total e média de respostas adequadas nos testes de simulação didática por AGF e por momento de aplicação.

Fonte: Placco, André e Gatti (2002). 
O Quadro síntese dos resultados mostra que de um total de 3375 respostas no primeiro momento da aplicação do teste apenas $1608(47,6 \%)$ eram adequadas, e de 3000 respostas, no segundo momento, $2065(68,8)$ eram adequadas. Verifica-se, portanto, um aumento de $21,2 \%$, o que nos parece um ganho significativo. Considerando-se o número médio de respostas adequadas por professor respondente, houve um aumento de 11,9 no primeiro momento, para 17,2 no segundo.

Assim, houve uma evolução nas opções didáticas desses professores cursistas, evidenciando que o PROFORMAÇÃO propiciou ganhos nas questões pedagógicas

\section{Mudanças na escrita dos memoriais}

Outro aspecto a ser destacado no desempenho dos cursistas, que foi evidenciado pela análise dos memoriais foi a evolução da escrita. Nos primeiros memoriais notase que o vocabulário é pobre, com repetições de palavras, os períodos são curtos, ligados por partículas coordenadas e as idéias expostas com simplicidade. Há muitos erros de ortografia, concordância e sintaxe. Seguem abaixo alguns exemplos:

Iniciei minha vida profissional aos 19 anos de idade. Comecei a
trabalhar no ano de 1984, em uma escola situada no distrito de [...
] Comecei trabalhando com a $1^{\text {a }}$ série. Eu não tinha a experiência
que tenho hoje e nem tinha acompanhamento para um bom de-
senvolvimento. (AGF Quixadá, Módulo 1, Unidade 1).
Descobri que os recursos está ao nosso lado, na nossa vivência (PC,
AGF de Gandu, Mod I, Unidade 1).
O estudo do módulo dois da unidade um está contribuindo para o
enriquecimento da minha aprendizagem porque cada área temáti-
ca estudada contribui bastante para o domínio dos conteúdos que
irei efetuar na minha sala de aula. (AGF de Feira de Santana,
Módulo II, Unidade 1).

Ao longo dos módulos percebe-se uma clara evolução seja na forma, seja no conteúdo dos memoriais. Por um lado, os cursistas enriquecem seu vocabulário com a incorporação dos termos dos Guias de Estudo e, por outro, melhoram substantivamente a forma de expressão das idéias: os períodos são mais longos, com o uso de partículas subordinadas, os erros de ortografia diminuem, assim como os de sintaxe. Embora ainda se encontrem alguns problemas, principalmente de pontuação, essa mudança é extraordinária, se considerarmos que os problemas de escrita que encontramos nos alunos que chegam ao ensino superior hoje, nem sempre são superados ao longo do curso.

Seguem alguns extratos dos memoriais referentes ao Módulos III e IV dos mesmos cursistas mencionados anteriormente:

É muito gratificante saber que já estou finalizando a terceira etapa do curso PROFORMAÇÃO. Sem dúvida foi muito positivo, tive muitos avanços durante este percurso. Foram muitos os momentos de alegria, mas também de aperto e angústia. Para mim os encontros dos sábados sempre foram de satisfação, encontrar-me com os colegas pcs e tutores e esperar ver em cada um sempre um sorriso de vitória. (AGF de Quixadá, Módulo III, Unidade 8). 
Neste do memorial aparece um vocabulário mais cuidado, construções mais elaboradas, indicando que ao escrever, orientada pelo tutor e pelos Guias de Estudo, a professora aperfeiçoa à sua escrita. Como ela mesma diz:

É com entusiasmo e confiança na capacidade adquirida a partir deste curso que me encontro registrando uma parte de minha história no último memorial relacionado ao PROFORMAÇÃO.

Os memoriais de outra cursista da Bahia também mostram uma clara evolução no vocabulário, mais rico e até sofisticado e uma estrutura mais complexa do texto, além de uma apropriação do conteúdo estudado:

[...] Procuro a cada dia construir redes de ricas interações, às quais cada um, à sua maneira, possa contribuir para que essas redes funcionem de instrumento de aprendizagem. (Módulo III, Unidade 7).

\section{Mudanças nos locais e nas políticas locais}

No longo período em que se acompanhou o Programa foi possível observar mudanças muito positivas das administrações locais quanto ao tratamento dado ao Proformação: algumas escolas foram pintadas, salas de aula reformadas, materiais pedagógicos disponibilizados, o pagamento dos salários dos tutores foi posto em dia, acabou a duplicidade de orientação (das Secretarias Municipais e do PROFORMAÇÃO) às professoras. Isso certamente ocorreu pela maneira como funciona a "engrenagem" do PROFORMAÇÃO: por um lado há uma tentativa de manter uma ação integrada dos componentes municipais, estaduais e federais, e, por outro lado, tem havido um esforço imenso de certos agentes, seja da Coordenação Nacional do PROFORMAÇÃO, seja das Agências Formadoras para resolver problemas eventuais no processo de implementação do Programa. Empenho e compromisso pessoal dos agentes têm sido importantes ingredientes no sucesso do Programa.

No memorial de uma cursista da AGF de Gandu, BA, fica muito evidente como uma ação coordenada da política local pode contribuir para o sucesso do Programa:

O programa criado para evitar que as crianças abandonem a escola foi de fundamental importância. Acho que houve um grande interesse político e social do prefeito municipal tendo como pontos de vida melhorar sua situação política e fazer uma transformação na vida dessas crianças que freqüentam a escola. Houve uma mediação através das prefeituras para ajudar essas pessoas; como, por exemplo, aqui mesmo em minha região houve uma grande transformação na vida dos alunos. Eles faltavam muito à escola para ajudar os pais na roça e na casa de farinha, não tinham um protetor de chuva, pasta para carregar os livros etc. E hoje tudo mudou, apesar de não ser um salário mínimo e sim uma pequena quantia, mas que já é de muita ajuda mesmo. (Módulo I, Unidade 3).

\section{Impacto social do Programa}

A visita aos locais que constituíram os estudos de caso permitiu-nos concluir que o Proformação vem atingindo áreas muito carentes do nosso país, em que dificuldades geográficas, climáticas, econômicas, se somam à precariedade de recursos materiais e humanos. 
A descrição das regiões em que estão localizadas as escolas estudadas revela que são marcadas pela pobreza, pela falta de saneamento básico, por população esparsa e falta de transporte público, por condições climáticas desfavoráveis, por escassez de alimentos e por inexistência de serviços públicos de saúde. Cercadas por tais condições adversas é que vivem e trabalham os cursistas do PROFORMAÇÃO, a maioria contribuindo de forma substantiva, com seu salário, para a renda familiar. Nessas circunstâncias, o Programa cumpre uma função social importante ao buscar melhorar a qualidade do atendimento escolar, através da qualificação dos professores que estão atuando nas escolas dessas regiões carentes e não têm a habilitação para o magistério.

A descrição do contexto de algumas escolas observadas ilustra essa situação:

A escola é um prédio com apenas uma sala de aula e está situada no povoado Sítio do Mestre, onde não há água tratada, nem encanada, as pessoas usam água de poço ou de tanque e por uma luta da comunidade conseguiram que a luz chegasse. Mesmo assim, a escola não tem luz [...] É um lugar muito pobre, com muitas necessidades. Próximo à escola, só há três casas e um delas é a da professora. As crianças caminham muito para chegar à escola. $\bigcirc$ prédio é cercado por uma vegetação própria do sertão, muitos cactos, palmas, lugar muito seco. Quando as crianças precisam satisfazer as suas necessidades, vão ao mato. É uma sala bem pequena para a quantidade de alunos. As carteiras ficam muito próximas umas das outras. (Diário de Campo de Feira de Santana, BA).

Esta escola fica numa fazenda de cacau na localidade chamada "Beira do Rio", a mais longínqua da sede do município. São quase $20 \mathrm{~km}$ de estrada de terra, precária, do tipo "se chove não entra, se chove não sai". Não há energia elétrica nesta região. A distância, a falta de transporte e a ausência de energia elétrica significam um enorme isolamento para esta comunidade. É difícil sair da Beira do Rio, não há acesso a noticiários e não há circulação de materiais escritos. A escrita está presente quase que unicamente em situações escolares. (Diário de Campo de Gandu, BA).

A escola está localizada no km 23 da estrada de Porto Acre, município localizado a 50 minutos de Rio Branco. Localizada no alto de um pequeno morro, a escola, toda de madeira muito desgastada e comida pelos cupins, possui duas salas amplas e com muitas janelas e uma cozinha só com uma pia. As poucas panelas, pratos e talheres ficam guardados no chão. Não há armário e a água que as crianças bebem é do poço da casa da merendeira. Da mesma forma, o banheiro também é precário, fica fora da escola, mas se apresentava bem limpo. (Diário de Campo de Rio Branco, AC).

A escola é composta por 2 salas, uma para a $1^{\circ}$ série (e pré-escola) e a outra para a $2^{\circ}$ série; um banheiro e uma cantina. Não tem telefone, mas podem recorrer ao telefone público, um orelhão, em frente ao portão. Não há pátio, e sim um quintal, de terra, com pouca vegetação. A sala de aula não tem janelas, mas buraquinhos quadrados de 10 por $10 \mathrm{~cm}$ que permitem a entrada de luz. A cantina é simples: um fogão, aliás são duas bocas com botiião; uma cisterna para armazenar a água, que atualmente chega somente de 8 em 8 dias; uma geladeira, com poucas garrafas de refrigerantes cheias de 
água. As prateleiras na parede acumulam canecas de plástico azuis, usadas pelas crianças e enormes panelões de alumio bem areados. $A$ escola estava há 4 semanas sem merenda. A servente relata: 'Tem dia que os meninos chega e pergunta se não tem ao menos um punhadinho de farinha, porque estão sem comer desde a noite anterior [...].' A escola se vê obrigada a liberar seus alunos mais cedo (por volta das 10:30/1 1:00 h, para que possam ir para casa almoçar). (Diário de Campo de Quixadá, CE).

Essas breves descrições permitem-nos constatar que as escolas em que lecionam os cursistas do Proformação são desprovidas de recursos, a começar pelos prédios precários em que funcionam, pelas salas de aula quase sempre exíguas, pela inexistência de material didático de apoio, pela falta de merenda. Nessas condições, o ensino fica quase que totalmente dependente do(a) professor(a), de sua boa vontade, de seu talento e criatividade. Essa constatação reforça a importância do Programa, não só por atingir regiões carentes do país, mas também pelo propósito de qualificação profissional dos professores, o que, dadas as condições apontadas, parece ser a forma mais adequada para conseguir a melhoria do processo de ensino aprendizagem e a elevação do desempenho escolar dos alunos.

Atingir áreas tão distantes e necessitadas do nosso país é um grande mérito do Programa.

\section{Referências}

ANDRÉ, M. Estudo de caso em pesquisa e avaliação educacional. Brasília, DF: Liberlivros, 2005.

BRASIL. Ministério da Educação. Secretaria de Educação a Distância.

PROFORMAÇÃO: Programa de Formação de Professores em Exercício. Brasília, DF, 1999. Disponível em: <http://proformacao.proinfo.mec.gov.br/>. Acesso em: 18 mar. 2008.

MAZZOTTI, A. J. A. Usos e abusos dos estudos de caso. Cadernos de Pesquisa, São Paulo, v. 36, n. 129, p. 637-651, set./dez. 2006.

HAMEL, J. Case study methods. Newbury Park, CA: Sage Publications, 1993.

MERRIAN, S. Case study research in education. San Francisco: Jossey-Bass Publishers, 1988.

STAKE, R. The art of case study. Thousand Oaks, CA: Sage Publications, 1995.

PLACCO, V. M. N. S.; ANDRÉ, M.; GATTI, B. A. PROFORMAÇÃO: relatório final geral da avaliação externa do Programa. Brasília, DF: PUC: FCC: MEC, SEED, 2002.

Recebido em: 21/11/2007

Aceito para publicação em: 27/02/2008 